\title{
Lifew orld-led learning takes place in the encounter between caring science and the lifeworld
}

\author{
Ulrica Hörberg ${ }^{1}$, Gunilla Carlsson ${ }^{2}$, Hanna Holst ${ }^{1}$, Niklas Andersson ${ }^{1,2}$, Camilla Eskilsson ${ }^{1,2}$, \\ Margaretha Ekebergh ${ }^{1,2}$ \\ 1. Faculty of Health and Life Sciences, Department of Health and Caring Sciences, Linnaeus University, Sweden. 2. School \\ of Health Sciences, University of Borås, Sweden.
}

Correspondence: Ulrica Hörberg. Address: Department of Health and Caring Sciences, Linnaeus University, SE-351 95 Växjö, Sweden. Email: ulrica.horberg@Inu.se

Received: Feburary 6, 2014

DOI : $10.5430 /$ cns.v2n3p107

Accepted: June 11, 2014

URL: http://dx.doi.org/10.5430/cns.v2n3p107
Online Published: June 23, 2014

\begin{abstract}
Learning in caring contexts could be illustrated as an encounter between the scientific knowledge of caring and the learner's lifeworld. This encounter needs a support that has the potential to bring caring science to life and to start an intertwining process with the lifeworld that creates embodied knowledge. The aim of this article is to illustrate the meaning of this encounter with help of a theoretical foundation and two examples of research projects with a reflective lifeworld research approach (RLR) founded on phenomenology. Both examples describe the student nurses' perspective. One illustrates promoting learning through lifeworld-led supervision in pairs of students. The other illustrates learning environments that bridges the gap between theory and practice. These two examples show how the intertwining of caring science theory with lived experience required a certain learning and caring atmosphere that is open and sensitive for the lifeworld. In conclusion, lifeworld-led learning is more than learning per se. Lifeworld theory as a basis for supporting students' learning could provide both a broadened and deepened understanding of the meaning of learning and also a greater understanding of how to support students' learning.
\end{abstract}

\section{Key word}

Caring science, Clinical nurse education, Learning environment, Lifeworld theory, Lifeworld-led learning

\section{I ntroduction}

Scientific knowledge is characterized by abstract descriptions and structures that are not immediately recognizable to the lived reality. Scientific knowledge cannot therefore be directly applied to the lived existence without being transformed and adjusted to the individual's very complex lifeworld ${ }^{[1]}$. Learning in caring contexts is an encounter between the scientific knowledge of caring and the learner's lifeworld. This encounter needs support that has the potential to bring caring science to life and to start an intertwining process with the lifeworld that creates embodied knowledge. Our purpose with this article is to illustrate the meaning of this encounter with help of a theoretical foundation and two examples of research projects. These projects empirically highlight the intertwining of theory with lived experiences in clinical learning environments. 


\section{Background}

\subsection{A science for caring}

Caring science has its focus on the patient's world and the patient perspective in relation to health and well-being ${ }^{[1]}$. By using a lifeworld theory foundation ${ }^{[2,3]}$ a greater understanding of a patient perspective can be developed. According to Husserl's philosophy ${ }^{[4]}$, the concept of the lifeworld denotes the way we understand ourselves and other people and everything else in the world. The lifeworld thus relates to an approach or attitude towards ourselves and the world around us. Consequently the lifeworld can be understood as the world as it is experienced. The lifeworld is the world we share with others but at the same time obviously personal and unique for each person. According to this philosophical foundation a lifeworld approach emphasizes the individual's experiences, which means paying attention to the patient's perspective of his/her suffering and well-being ${ }^{[1]}$. Caring science has thus its focus mainly on existential issues concerning the patient's world, and a holistic view that distances itself from dualism and polarization. The patient is seen as a lived body that includes all human aspects. It means for example that biological and medical aspects are recognized in the same way as everything else in the patient's world. Caring based on caring science has the capacity to meet and understand the lifeworld and support well-being, which is to support life-processes ${ }^{[1]}$.

\subsection{Lifeworld-led didactics - didactics based on caring science}

Different types of encounters occur between caring science and the lifeworlds of those involved in caring contexts. These encounters are learning encounters and the challenge is to transform caring science knowledge in becoming a tool to comprehend the lifeworld of the more deeply, but also to use the lifeworld to comprehend the scientific knowledge. It is a movement between the theoretical dimension and the lived dimension, created by the tension in the encounter ${ }^{[5,6]}$. The encounter between caring science and the lifeworld requires a certain form of didactics in order for it to support the learning process. This entails didactics that have the potential to consider the learner's experiences and understanding of what is in focus for learning. In other words it entails paying attention to the learner's perspective in the same way as paying attention to the patient's perspective in the caring context. Lifeworld-led didactics are thus based on the same ontological and epistemological foundation as caring science, which entails a holistic view based on lifeworld theory ${ }^{[5,7,8]}$.

Lifeworld-led didactics consider the learners' lifeworld and are characterized by being open and sensitive for the learner's

view and experiences ${ }^{[6,9,10]}$. Learning is individual and takes its point of departure in the learner's previous experiences, which accompanies the learning process. It is thus crucial to be sensitive to the learner's horizon of understanding and his/her reflection and knowledge. Reflection is necessary for the understanding process ${ }^{[10]}$, and it entails keeping a distance from the natural attitude, from the obvious and that which is taken for granted and starting a conscious activity concerning experiences, thoughts and feelings with the purpose of developing a new understanding.

\subsection{Learning environments}

Lifeworld-led didactics play an essential role in learning environments in caring practice. A learning environment is essentially a place for supervision and reflection, but the concept even includes the persons who are involved and their interplay in learning activities. The meaning of learning environments encompasses both intersubjectivity and spatiality. It is a space for conscious reflection and supervision that creates an atmosphere with good opportunities for learning. This type of environment 'is lived' by the persons involved, which includes both the learners and the supervisors or teachers ${ }^{[11]}$. In learning environments the didactics are flexible in response to the learner's lifeworld and to the caring science matter so that the development of the understanding of the patient's world, the caring and the practical knowledge can be permeated by this knowledge base. This can, for example, entail caring science concepts, such as; a patient perspective, wellbeing, suffering, caring relationship and so on, forming the tools to penetrate the patient's narrative and to develop an understanding of the patient's world ${ }^{[7]}$. With lifeworld-led didactic strategies the learner can acquire adequate knowledge from practice at the same time as having a caring approach. The latter is based on a caring science perspective, is 
developed and can be capable of permeating thoughts, feelings and actions in the learning process ${ }^{[12]}$, which means an interweaving process, where caring, ethics, specific professional knowledge, and the patient's world are the core components.

\section{Reflective lifeworld research}

The two examples of research projects, which are presented in this article, have been carried out with a reflective lifeworld research approach (RLR) founded on phenomenology ${ }^{[13]}$. The focus of these projects have been on the acquisition of caring science knowledge in caring contexts, and more precisely it is the encounter between caring science and the lifeworld. RLR is grounded in the continental philosophy of Husserl ${ }^{[2,3]}$ and Merleau-Ponty ${ }^{[14,15]}$ and in order to use RLR it is necessary to transform the phenomenological epistemology into a scientific approach. It is important to have openness and flexibility towards the phenomenon that is studied, which means having a reflective attitude and not understanding too quickly, and allowing the phenomenon to present itself ${ }^{[16]}$. This reflective attitude has been developed by Dahlberg ${ }^{[17,18]}$ and is described as a bridling of the understanding process ${ }^{[13]}$. The analysis according to RLR is to search for and describe the meaning of the phenomenon, its variations in meaning and essential meaning structure, which can be described as a movement between the whole - the parts - the whole ${ }^{[13]}$. The analysis starts by searching for meanings in the transcribed data. After this related meanings are grouped together in clusters, based on similarities and differences. In the next phase clusters are related to each other and a search for patterns of meanings starts with the purpose of finding the phenomenon's essence i.e. its' essential meanings.

The first example is based on two studies ${ }^{[19,20]}$ with the aim of describing the learning process of student nurses when supported by supervision in pairs. The studies have different foci. The first study ${ }^{[19]}$ focuses on encounters with patients and the second study ${ }^{[20]}$ focuses on their (student nurses) professional role. The second example is also based on two studies with the aim of describing how caring and learning is intertwined from a student perspective in both a psychiatric ${ }^{[21]}$ and an orthopaedic care context ${ }^{[22]}$. The data in the examples was collected in lifeworld interviews ${ }^{[13]}$ with student nurses (in the undergraduate nursing programme) and by participatory observations of student nurses' encounters with patients. Data was also collected from student nurses' diary entries. The students were interviewed individually, in pairs or in groups. In total 48 student nurses were interviewed, 20 of these also wrote diary entries and 15 were also observed with follow-up interviews. More specific descriptions of each study are provided in Table 1.

Table 1. Data descriptions of each included study

\begin{tabular}{|c|c|c|c|c|c|}
\hline Study & Data collection & Informants & Women & Men & Context \\
\hline \multirow{3}{*}{$\begin{array}{l}\text { Holst \& Hörberg, } \\
2012\end{array}$} & 6 interviews in pairs & \multirow{3}{*}{12} & \multirow{3}{*}{12} & \multirow{3}{*}{0} & Developing and \\
\hline & & & & & Learning Care Units \\
\hline & 12 diary entries & & & & in psychiatric care \\
\hline $\begin{array}{l}\text { Holst \& Hörberg, } \\
2013\end{array}$ & 6 interviews in pairs & 12 & 12 & 0 & $\begin{array}{l}\text { Developing and } \\
\text { Learning Care Units } \\
\text { in general hospital } \\
\text { care }\end{array}$ \\
\hline \multirow{3}{*}{$\begin{array}{l}\text { Andersson \& Ekebergh, } \\
2013\end{array}$} & 11 individual interviews & \multirow{3}{*}{15} & \multirow{3}{*}{11} & \multirow{3}{*}{4} & \multirow{3}{*}{$\begin{array}{l}\text { Dedicated educational } \\
\text { units in psychiatric } \\
\text { care }\end{array}$} \\
\hline & 18 participatory observations & & & & \\
\hline & 8 diary entries & & & & \\
\hline $\begin{array}{l}\text { Eskilsson, Hörberg, } \\
\text { Ekebergh \& Carlsson, } 2014\end{array}$ & 7 individual interviews & 13 & 12 & 1 & $\begin{array}{l}\text { Dedicated educational } \\
\text { units in orthopedic } \\
\text { care }\end{array}$ \\
\hline
\end{tabular}




\section{Two examples of research projects}

\subsection{Promoting students' learning through lifeworld-led supervision in pairs of students}

The first example is based on two studies ${ }^{[19,20]}$ with a learning based on the model of the Developing and Learning Care Unit, a structure to support nursing students in their learning process when supervised in pairs. The guiding principle in this model is reflection, both individually and in groups. The model is based on a supervision team, whose work is characterized by a reflective approach. The team consists of one base supervisor (nurse) who supervises students in the bedside area, one main supervisor (nurse) with an overall responsibility for students' clinical studies and also the role of providing support to both students and base supervisors, one teacher (lecturer from the nursing education) who is the bridge between theory and praxis and carries out assessments of students together with the main supervisor. The students are also supervised in groups by the main supervisor and the teacher on a few occasions during the clinical practice. Each unit has one main supervisor, several base supervisors and one teacher linked to it ${ }^{[6]}$.

The overall aim of these studies was to describe the learning process of students, when supervised in pairs of students. This overall aim is related to the essential meanings of the phenomenon "student's learning when supervised in pairs", in accordance with the phenomenological approach. A descriptive summary of the two results on an essential level is presented below.

Supervision of a pair of students most often appears to be an asset for students' learning in terms of the security felt by the students that creates a favorable environment for them to dare and venture to take initiatives and be independent in caring, while it has also been shown to be a sensitive and vulnerable phenomenon. Being supervised in pairs is important for the students' learning process where they can recognize themselves in each other, feel security, interact and where reflection plays a major role. Reflection in all its forms is shown to be a tool for the students' learning in pairs where they dare to reveal their lack of knowledge to each other which gives them a chance to learn from each other but also to work together to find their own way of caring. Working together can imply giving space to the other in the pair at the expense of one student's own learning and as a part of this cooperation the students learn to give and take in their joint learning process.

Learning in pairs of students involves responsibility and is seen as important for the students' learning. The student pairs describe that the more responsibility they receive from the supervisor the more responsibility they can take on by themselves, this generates a feeling of being careful and capable when caring for the patient. This responsibility can be experienced as balancing between wanting to take it and daring to take it. When students get too much responsibility they can easily feel abandoned, which can lead to feelings of stress, anxiety and insecurity. Responsibility is a focal point in learning in the progress towards becoming a professional nurse, a responsibility that has to include student vulnerability in the performance of their theoretical knowledge in clinical practice. Responsibility is experienced as being an important part of how students are supervised in pairs. The inter-subjective relationship between pairs of students and their supervisor has to be handled with sensitivity in order to create a balance in giving the right amount of responsibility. The supervisor's ability to meet the students' lifeworld is therefore crucial for creating a successful support of their learning process.

The supervisors' ability to provide a balanced support to students is based on their ability in being present and confirmatory, but not prominent, but waiting and giving time for reflection. This provides the students with a feeling of security and an opportunity for them to develop towards a professional nursing role. Supervisors that do not have this ability to create time and space for the students' learning could lead to inhibited learning that generates stress, resignation and reservation among the student nurses. A supervisor's "help” then appears as having the opposite effect on the students' learning and disrupts the learning process. Optimal supervision plays a great and definitive role in the students' learning process and in supporting students in developing towards their professional role. Supervisors who understand the students' 
perspective and inspire them to feel self-confident with a reflective supervising attitude are experienced as an asset. Group supervision, where several pairs of students participate, is also experienced as an asset in students learning and is described in terms of the learning starting in the meeting with the patient and through reflection and supervision in groups the caring science is brought to life and understood.

\subsection{Learning environments that bridge the gap between theory and practice}

The second example of research projects is based on two studies ${ }^{[21,22]}$ and highlights innovative learning environments that bridge the gap between theory and practice. The focus is on the interplay between caring and learning. The research question is how caring becomes learning and vice versa. This question is studied from three perspectives; the nurse students, nurse supervisors and patients. The project has been carried out in two dedicated educational units (DEU), one in psychiatric care and one in orthopedic care. These units are based on caring science and are characterized by a high level of qualified learning support with a focus on reflection ${ }^{[11]}$. The clinical studies in the psychiatric care unit are into their second year in the nursing educational program and in the final clinical training period in the orthopedic care. This project is ongoing and findings from the nursing students are described in this paper. The findings demonstrate the students' lived experiences of caring and learning and are related to essential meanings of the phenomenon "the interplay between caring and learning”, in accordance with the phenomenological approach.

How caring becomes learning and how learning becomes caring on a DEU in psychiatric care ${ }^{[21]}$ concerns getting to know the patient, but also about getting to know oneself and the caring environment by asking questions and searching for answers. The search involves being in a transitional movement towards new horizons of wider and deeper understanding. Being in transition entails moving between pre-understanding and new in-depth understanding, between the seemingly unknown and the known, and between the unfamiliar and familiar. Embedded in the pre-understanding are uncertainty and insecurity prior to the encounters with the environment and the people who represent the unknown and the different. In the pre-understanding is also curiosity as in the desire to want to know and care, as in the desire to do the best for the patient. Together these constitute the driving force that stimulates the search for certainty and understanding. The search for answers continues through internal dialogue aimed at interpersonal encounters. The answers do not come immediately, embedded in the ongoing movement in transition. New questions about uncertainty are formulated like a spiral, which has no clear start and end. In the search for answers there is an ambition to try to understand. It is in this attempt to understand and through recognition, that caring and learning is born, nurtured and developed. In the searching for understanding there are needs of support from supervisors. How caring becomes learning and vice versa is, however, not solely dependent on the supervisor's support. When the student gains an insight into searching alone without support, he/she takes the initiative to encounter the patients themselves with the help based on curiosity and the desire to care.

The other example ${ }^{[22]}$ which is from a DEU with orthopedic care shows that caring and learning occurs in an atmosphere filled with inviting challenges. The atmosphere is accompanied by a sensitivity to maturity and needs for intertwining theory with practice. Caring and learning meet in a fruitful collaboration since it is vivid in an atmosphere of response that offers inviting challenges. In order to create optimal caring and learning an atmosphere of safety and support for the student is necessary as well as a confirming and affirming response. Supervisors, who exude a sense of feeling safe and who have the ability to balance between being both an agent of surveillance and permission, can actively create an atmosphere of safety and support for the student. The students' understanding and ability in nursing care is challenged and when they are confirmed in being on the right track, they are motivated to develop in responsibility and independence.

The students appreciate the relationship with the patient as a part of their caring and learning process. The response given from the patient guides the student to be aware of both their approach and skill. Meeting patients means that theory falls into places and meaning and coherence occur. Theoretical knowledge and practical exercise form a base but can never replace the real meeting with patients. Interplaying with the patient means learning both a caring attitude and practical skills that would have been impossible without the patient. 
Students are driven towards the goal of becoming a nurse in their own personal style. They try to find themselves. In order to find one's own way it is necessary to develop into more independence and confidence. It is both liberating and frightening to search for one's own style and to grow into a new role. The atmosphere may consist of both security and pressure and encourage the students to meet challenges of taking responsibility and solving problems. Taking more responsibility makes them feel more as nurses and theory and practice fit together.

\section{Reflections on the intertwining of caring science with lived experiences of caring and learning in clinical learning environments}

These two examples show how the intertwining of caring science theory with lived experience required a certain learning and caring atmosphere that is open and sensitive for the lifeworld. This becomes visible in relation to students' learning and to patients' wellbeing, when caring science is implemented in a caring context. This is supported by several research studies where the clinical environment as a learning environment is focused on ${ }^{[23,24]}$. The students' need for reflection appears to be obvious in the intertwining process. Through reflection the students are searching for an understanding of the patient's world and the caring context. They are also driven to develop an awareness of themselves, their own thoughts and feelings and self-confidence. They have to remain in this reflection process because the answers and understanding is slowly developed and new questions can always arise. The importance of reflection for students' learning has been expressed in previous studies ${ }^{[25,26]}$. Research within caring science didactics ${ }^{[6,8,27,28]}$ has developed a reflective supervision model. The starting point for this supervision is the patient's narrative, which is penetrated and analysed by using caring science concepts such as; a patient perspective, wellbeing, suffering, caring relationship and so on, with the purpose of perceiving the patient's health condition and understanding the patient's world in a more profound way. A plan for appropriate caring activities is then formed. This reflection model supports an interweaving of theoretical concepts with the patient's lived experiences and knowledge in practice. The research referred to above has shown that caring science concepts are an important tool in this learning reflection and for gaining a greater understanding of the patient's world. A pre-condition is, however, that the support in the learning process is such that the student's lifeworld is taken into consideration in the same way that the patient's lifeworld is taken into consideration in the caring. Ranheim and Dahlberg ${ }^{[29]}$ propose that it is important for nurses to develop an expanded awareness which includes a sense of acuity, self-awareness and self-confidence in order to be able to meet patients' unspoken needs and to be sensitive towards patients' existential concerns. Ranheim ${ }^{[30]}$ also maintains that it is possible to link caring science with practical everyday care which requires both an increasing self-awareness and a greater theoretical knowledge in relation to lived experiences of care. The supervisor thus needs to have this knowledge to successfully support student nurses in developing an expanded awareness i.e. a caring attitude. Consequently learning and caring are parallel processes, which are important in the reflective intertwining process.

The students feel responsibility for both their own learning and the caring for the patients. The responsibility activates their learning. Too much responsibility can however cause stress, insecurity and anxiety. The supervisors play a fundamental role here to balance the responsibility of the students and to support them in their learning and caring development. They need supervision in the encounter with the patient and how to create a caring relation. They also need support in their reflection and they need response about their thoughts and caring activities ${ }^{[10]}$. According to Fang, Jipping, Dan, Yangjuan and Jianhua ${ }^{[31]}$ it is important to reduce exposure to negative role models and to develop appropriate didactic ideas about how to learn in clinical practice, such as truth telling and helping students to think in a critical manner. The challenge is thus to create an atmosphere that is confirming and supporting, which need a clear balance between the supervisors' attendance and absence in the learning and caring context ${ }^{[32]}$. The two examples of research projects are carried out in learning environments that are designed specifically to support students' learning, with an endeavour to intertwine theory and practice. This may indicate that these learning environments can provide favourable opportunities for learning in caring. From these two examples we can see that the learning (as well as the caring) takes place in the interspace between 
students, patients and supervisors. This space can be further understood in relation to Merleau-Pontys philosophy of the lived body ${ }^{[14]}$ and with his words "The body is the vehicle of being in the world" (p. 82) which means that we meet each other as lived bodies and the space can be expressed as an intersubjective meeting place between lived bodies. Those intersubjective meetings between student-student, student-patient, and student-supervisor are thus of importance for students' learning because the learning takes place in this space ${ }^{[20]}$. In order to reach embodied knowledge and to learn, students need to be supervised in ways that evoke reflection within these intersubjective-meetings, with the goal to develop a reflective attitude that could be expressed in a caring attitude ${ }^{[1,10]}$.

In relationship to other human beings we are affected in our being in the world, and at the same time we affect other human beings in the same world. This could be understood in accordance to Merleau-Pontys ${ }^{[15]}$ illustration of "the flesh of the world" which means that both existences and matter are affected by the same world because that they are from the same "flesh". If we transformed this philosophical "flesh" or with other words "an interlaced world" to the students learning environment it becomes clear that we cannot separate the student and his/her learning from the environment or from the supervisor's skills and capabilities to support students' learning. Neither can we separate supervisor's skills in supporting students learning from the prerequisites the healthcare organization provides to supervisors. Thus, the support to students' learning cannot be limited to the relationship between student's and supervisors. The patients have an important role in the students learning by allowing the students to take care of them and also the organization of the ward is of importance. The educational program has the responsibility for the quality of the education in clinical practice. Taking this responsibility required collaboration between theory and practice i.e. in the clinical practice between educators and supervisors. We have thus to give consideration to the clinical education in order to build a solid ground for students' learning in collaboration between the clinic and practice in order to avoid the students' learning becoming random.

The two examples of research project have been performed in caring contexts where both the caring and the learning models are based on a lifeworld perspective as described by Dahlberg and Segesten ${ }^{[1]}$ and Ekebergh ${ }^{[6,10]}$. Dahlberg, Todres and Galvin ${ }^{[33]}$ maintain that lifeworld-led healthcare is more than patient-led care and express it as "the existential view of well-being that we offer is pivotal to lifeworld-led care in that it is intrinsically and positively health focused in its broadest and most substantial sense” (p. 265). This could provide an understanding of the meaning of a lifeworld led learning where the student's lifeworld is the focal point of how learning can be supported. However, from a critical point of view it might be a limitation that learning and reflection in our examples have only been studied from one epistemological perspective, a phenomenological lifeworld perspective. There can be other theoretical frameworks for these phenomena and with other underpinning theories another study might come to other results concerning the meaning and explanation of learning and reflection, and thus develop knowledge different to that in the present study. Our intention, however, with this article is to contribute to a comprehensive understanding of the learning process and the importance of reflection in order to intertwine theory with practice in caring contexts.

\section{Conclusion}

In conclusion, from this point of view we maintain that a lifeworld-led learning is more than the learning per se. The justification is that the lifeworld theory as a basis for supporting students' learning provides a broadened and deepened understanding for the meaning of learning and also a greater understanding of how to support students' learning. Learning and caring should thus be seen as parallel processes as well as intertwined, where the learning takes place when the students care for patients. An optimal learning requires a learning environment that gives space for reflection and intersubjective meetings between the students-patients-supervisors.

\section{Conflicting interest}

The authors declare that they have no competing interests. 


\section{References}

[1] Dahlberg K, Segesten K. Hälsa \& Vårdande i Teori och Praxis. [Health and caring in theory and practice]. Stockholm: Natur \& Kultur; 2010: 13-255.

[2] Husserl E. Cartesian meditations: an introduction to phenomenology. (D. Cairns, Trans.). The Hague: Martinus Nijhoff. 1977/1929: 27-157. http://dx.doi.org/10.1007/978-94-009-9997-8

[3] Husserl E. The crisis of European sciences and transcendental phenomenology. (D. Carr, Trans.). Evanston, IL: Northwestern University Press. 1970/1936: 3-265.

[4] Husserl E. Experience and judgment: investigations in a genealogy of logic. Evanston: Northwestern Univ. Press; 1973.

[5] Ekebergh M. Developing a Didactic Method that Emphasizes Lifeworld as a basis for learning. Reflective Practice. 2009a; 10(1): 51-63. http://dx.doi.org/10.1080/14623940802652789

[6] Ekebergh M. Att lära sig att vårda med stöd av handledning. [Learn to care with support of supervision]. Lund: Studentlitteratur. 2009b: 15-213.

[7] Ekebergh M. A Learning Model for Nursing Students during Clinical Studies. Nurse Education in Practice. 2011; 11: $384-389$. PMid:21489878 http://dx.doi.org/10.1016/j.nepr.2011.03.018

[8] Dahlberg K, Ekebergh M. To use a method without being ruled by it: Learning supported by drama in the integration of theory with healthcare Practice. The Indo-Pacific Journal of Phenomenology. 2008; 8: 1-20.

[9] van Manen M. The tact of teaching: the meaning of pedagogical thoughtfulness. Ann Arbor, MI: The Althouse Press. $1991: 3-240$.

[10] Ekebergh M. Lifeworld-based reflection and learning: a contribution to the reflective practice in nursing and nursing education. Reflective Practice. 2007; 8(3): 331-343. http://dx.doi.org/10.1080/14623940701424835

[11] Ekebergh M. Dedicated Educational Unit: A Scandinavian model. I: K Edgecombe, M Bowden (Eds). Clinical Learning and Teaching Innovations in Nursing. Dedicated Education Unites Building a Better Future. London: Springer. 2013; $123-130$.

[12] Petersson B-O. Handledning för vårdare: ett lärande möte utifrån patientens värld. [Supervision for health care professionals: a learning meeting from the patients’ lifeworld]. (Licentiate dissertation). Möndal: Department of Health and Caring Sciences, Linnaeus University; 2010: 10-123.

[13] Dahlberg K, Dahlberg H, Nyström M. Reflective Lifeworld Research. Lund: Studentlitteratur. 2008: 29-350.

[14] Merleau-Ponty M. Phenomenology of perception. (C. Smith, Trans.). London: Routledge. 2002/1945: 77-530.

[15] Merleau-Ponty M. The visible and the invisible. (A. Lingis, Trans.). Evanston, IL: Northwestern University Press. 1968/1964: 3-162.

[16] Dahlberg H, Dahlberg K. To not make definite what is indefinite. A phenomenological analysis of perception and its epistemological consequences in human science research. Journal of the Humanistic Psychologist. 2003; 31(4): 34-50. http://dx.doi.org/10.1080/08873267.2003.9986933

[17] Dahlberg K. The individual in the world - The world in the individual': towards a human science phenomenology that includes the social world. Indo-Pacific Journal of Phenomenology. 2006; 6: 1-9.

[18] Dahlberg K. The essence of essences - the search for meaning structures in phenomenological analysis of lifeworld phenomena. International Journal of Qualitative Studies on Health and Well-being. 2006; 1(1): 11-19. http://dx.doi.org/10.1080/17482620500478405

[19] Holst H, Hörberg U. Students learning in an encounter with patients: Supervised in pair of students. Reflective Practice. 2012; 13(5): 693-708. http://dx.doi.org/10.1080/14623943.2012.670623

[20] Holst H, Hörberg U. Students learning in clinical practice, supervised in pairs of students - a phenomenological study. Journal of Nursing Education and Practice. 2013; 3(8): 113-124. http://dx.doi.org/10.5430/jnep.v3n8p113

[21] Andersson N, Ekebergh M. How do encounters between students and patients become both caring and learning? Poster presented at the EACS conference, University of Aarhus, Denmark April 10th, 2013.

[22] Eskilsson C, Hörberg U, Ekebergh M, Carlsson G. Student nurses’ experiences of how caring and learning is intertwined - A phenomenological study. Journal of Nursing Education and Practice. 2014; 4(2): 82-93.

[23] Papp I, Markkanen M, von Bonsdorf M. Clinical environment as a learning environment: student nurse’s perceptions concerning clinical learning experiences. Nurse Education Today. 2002; 23: 262-268. http://dx.doi.org/10.1016/S0260-6917(02)00185-5

[24] O’Mara L, McDonald J, Gilliespie M, Brown H, Miles L. Challenging clinical learning environments: Experiences of undergraduate nursing students. Nurse Education in Practice. 2014; 14: 208-213. PMid:24063792 http://dx.doi.org/10.1016/j.nepr.2013.08.012

[25] Todres L, Galvin K, Holloway I. The humanization of healthcare: A value framework for qualitative research. International Journal of Qualitative Studies on Health and Well-being. 2009; 4: 68-77. http://dx.doi.org/10.1080/17482620802646204 
[26] Severinsson E, Sand Å. Evaluation of the clinical supervision and professional development of student nurses. Journal of Nursing Management. 2010; 18: 669-677. PMid:20840361 http://dx.doi.org/10.1111/j.1365-2834.2010.01146.x

[27] Hörberg U, Ozolins L-L, Ekebergh M. Intertwining caring science, practice and caring education from a lifeworld perspective: two contextual examples. International Journal of Qualitative Study on Health and Well-being. 2011; 6: 10363. PMid:22171223 http://dx.doi.org/10.3402/qhw.v6i4.10363

[28] Hörberg U, Ozolins L-L. Film as support for promoting reflection and learning in caring science. Indo-Pacific Journal of Phenomenology. 2012; 12:12 pp.

[29] Ranheim A, Dahlberg K. Expanded Awareness as a Way to Meet the Challenges in Care that is Economically Driven and Focused on Illness: A Nordic Perspective. Aporia: The Nursing Journal. 2012; 4(4): 20-24.

[30] Ranheim A. Caring and its ethical aspects: An empirical philosophical dialogue on caring. International Journal of Qualitative Studies on Health and Well-being. 2009; 4: 78-85. http://dx.doi.org/10.1080/17482620902727300

[31] Fang M, Jipping L, Dan Z, Yangjuan B, Jianhua S. Confronting the caring crisis in clinical practice. Medical Education. 2013; 47: 1037-1047. PMid:24016174 http://dx.doi.org/10.1111/medu.12250

[32] Berglund M, Sjögren R, Ekebergh M. Reflect and learn together - when two supervisors interact in the learning support process of nurse education. Journal of Nursing Management. 2012; 20: 152-158. PMid:22380410 http://dx.doi.org/10.1111/j.1365-2834.2011.01368.x

[33] Dahlberg K, Todres L, Galvin K. Lifeworld-led healthcare is more than patient-led care: an existential view of well-being. Medicine, Health Care and Philosophy. 2009; 12: 265-271. PMid:19101822 http://dx.doi.org/10.1007/s11019-008-9174-7 